\title{
Study on Rural Environment Design Based on Public Art Aesthetics Perspective
}

\author{
Juan Yang \\ Lijiang College of Guangxi Normal University, 541006 Guilin, China
}

\begin{abstract}
It has put forward the beautiful rural construction in the report delivered at the18th National Congress of the Communist Party of China after the high speed urbanization and modern urban environment construction. With profound cultural deposits, the rural area is the virgin land of regional feature and local civilization and also the source of beautiful homesickness. However, the rural public art is an important symbol and reflection of rural mature development. This paper analyzes the existing problems of rural environmental engineering construction and puts forward the corresponding solutions and development strategies on the basis of the rural public art and practical significance, thus opening up the new thinking for the design and construction rural environment engineering.
\end{abstract}

\section{Introduction}

It has gained rapid development and achieved good results in the urban construction since the reform and opening-up policy. It has brought good news for the rural construction in the report delivered at the18th National Congress of the Communist Party of China. The beautiful rural plan aims to change the dirty, chaotic and broken rural appearance and the rural appearance will have optimization and construction fund investment. Literally in the words "beautiful rural area", it will change the dirty, disorderly and bad rural area and make it beautiful. The ultimate goal of rural changes is "beauty". So what can be called the beautiful rural area? How to carry out rural construction in order to make it beautiful? There various meanings of rural beauty. The beauty of mountain, water and landscape is a kind of natural beauty. The beauty of house, road and living facilities is a kind of humanistic beauty. The friendly, hygienic, neat and tidy and civilized village is a kind of quality beauty. This paper studies the beautiful rural area and environment construction from the perspective of public art aesthetics, wake up the rural aesthetic consciousness and re-understands the value and mission of rural civilization through the studies on the display of rural aesthetics art work in the open space and puts forward the corresponding solutions and development strategies through the analysis of the existing problems in rural environmental engineering construction, thus opening new thinking for the construction and development of rural environment.

\section{Public Art Aesthetics}

\subsection{Basis connotation of public art aesthetics}

Public art refers to the work or design work for a certain space public space created by artist, which is an important symbol and reflection of mature development of a certain area. The public art increases the aesthetic significance and spiritual wealth of an area, conveys the local identity and cultural value in a positive sense and reflects people's sense of identity and sense of pride for regional culture. The civil investigation and statistics from 2010 to 2018 shows that the public art in Weinan Region has been paid more and more attention in rural construction and is in steadily rising status(as shown in Figure1).The static expression form of rural public art is the rural landscape art while the dynamic expression forms include the art performance, folk-custom activity and country music on the rural stage.

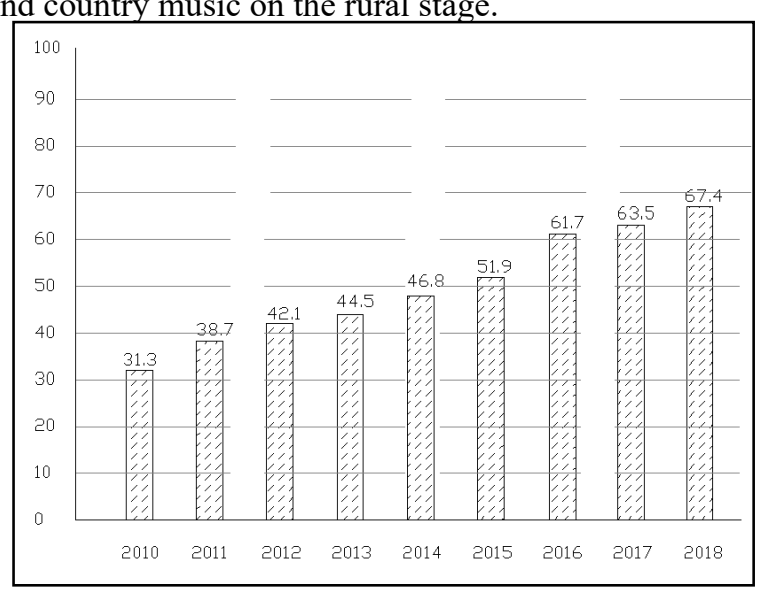

Figure1 Investigation on importance degree of public art 


\subsection{Significant value of rural public art aesthetics}

\subsubsection{Times}

The development space of traditional rural environment construction is affected by various factors due to its dependence on natural conditions, such as the low technical level, rigid expression form, purpose of solving the problem of food and clothing and lack of aesthetic feeling.

With the continuous development of science and technology and the continuous evolution of people's thinking, our society has entered the era of rapid informatization development. The digital and rapid development status is an inevitable trend of the development of times currently. As a result, the rural environment construction integrated with digitalization and art integration that is quite different from the traditional rural construction is a great leap and the presentation of times.

\subsubsection{Innovation}

The innovation of rural public art aesthetics is a derivative of the times, which is characterized by times and artistic nature. First, the times calls for innovation and the continuous innovation is the main feature of times currently. Second, the art calls for innovation. The house and road can be built of the same pattern if the rural environment is based on the demand for physical function, which is time saving and labor saving. The different but coordinated design of the house, road and landscape with integrated visual effect based on the demand for art aesthetics can be achieved after continuous innovation.

\section{Analysis of rural environmental engineering problem}

The human factor, environmental factor, facility factor and cultural factor are involved in the humanization of public art. Therefore, the humanization involved in the rural environment engineering should contain the dynamic factor, such as folklore activities, etc. It is necessary for the designers to fully analyze and use these factors for the rural public art design and study the strategies for rural environmental engineering from the perspective of human factor, project factor, activity factor, etc

\subsection{Poor peasant quality and insufficient development consciousness}

The proverb goes that "The mountains are beautiful, so is the river, but the most beautiful are the people here". However, people will have beautiful behavior and appearance only with beautiful awareness. It is impossible for a dirty-minded person to have the spirit of dedication and kindness. Similarly, it is impossible for a peasant who strives for ample food and clothing to construct and beautify the rural environment. The peasants have poor quality and inadequate development consciousness because of their deep-rooted small farmers' way of thinking. It can guarantee the smooth implementation of rural environmental engineering construction and maintain the long term life vitality, thus achieving the beautiful legend of "beautiful mountain and river and more beautiful people" only when the peasants realize the significance of environment construction.

\subsection{Confused project planning and poor environmental protection}

The development of rural environment mainly lies in development and protection. Currently, the rural environment construction only focuses simple environment development with no corresponding environment protection from the status of rural environment development. However, it is believed that the environment development with no protection is a damage to the environment. The rural environment project is in an unplanned status. For example, the rural greening engineering, road infrastructure, living water, production water supply and garbage disposal are not corrected and improved under the dirty, disorderly and bad rural environment.

\subsection{Single activities and lack of motivation}

Public art is an open art. The public art requires not only the physical matching but also the spiritual matching from the rural environment. Currently, with the single spiritual activity and fixed life form, peasants often have their family life spiritually of watching TV and even large festival and the New Year folk-custom activity. These fixed and rigid activities fail to meet people' rich spiritual demands nor conform to the requirement of new rural development in the new era. The backward spiritual life restricts the popularity of public art aesthetics and the artistic development of rural environment construction, thus making the rural environment construction far behind the urban environment construction.

\section{Countermeasures for the development of rural environment design engineering}

\subsection{Comprehensive training to improve pleasant quality}

To improve the peasant quality and update peasant consciousness is the key work of beauty work for beautiful rural environment. It is the future development direction of rural environment protection and development to open up new rural environment while breaking peasants' traditional idea for environment. First, the relevant leading units should actively give financial support, organize the educational agencies for the 
teaching activities of environment protection and construction and promote the environment aesthetics ideas to the local residents as well as the renewal of their traditional thinking, this improving the quality of peasants. Second, the relevant units should carry out the evaluation work regularly, know their learning progress, learning status and effect and have regular education among the peasants, thus achieving the effective aesthetic education. Third, it is a long process to carry out the quality education among peasants. The government sector should insist on the long term and effective education among the peasants and take it as a daily work. Only in this way can they be well influenced by the knowledge and thinking, make progress and become the peasants of the new times.

\subsection{Emphasis on project planning, combination of protection and development}

The key work in rural environment is the project planning and construction. Currently, the superior leaders and subordinate workers do not fully implement the rural project planning as a key work. Particularly, the superior leaders fail to cope with the problems in rural planning and project construction and project construction nor give supporting regulatory plan. They have no action for the rural environment construction. The rural environment work based on the guiding concept of public art aesthetics can solve the most urgent problems first. For example, for the water pollution treatment of living water, it strictly controls the rural water pollution caused by the industrial water pollution and air pollution, focuses on the water environmental quality and ensures the drinking water safety. Second, it spares no efforts to improve the rural production and living environment and focuses on the clean homeland, clean water and clean countryside. Taking the preventive treatment of soil pollution as the key point, it promotes the development of environment protection and construction, thus improving the rural life quality and living standards by relying on the guiding concept of public art aesthetics.

\subsection{Development of art activity, creation of spiritual civilization}

Rural environmental engineering construction from the perspective of public art aesthetics includes not only the environment protection and construction traditionally but also rural atmosphere creation and spiritual civilization creation. The creation of rural atmosphere needs to conform to the requirements of times development, reflecting not only the traditional idea of family harmony but also the active innovation exploration, but also fashion, agriculture and technology. Nowadays, people are always in the pursuit of high quality spiritual life and physical life under the high quality spiritual life, thus reaching their expectation and really improving their life quality.

Art activity is an important part of people's daily life in essence. Community governments and leading units of various levels should formulate reasonable and practical regulations and hold the rational spiritual activities according to the rural population distribution and development status. For example, they should carry out the May Fourth movement, singing contest, recitation contest and other forms of recreational activities. These rich activities are easy to be accepted by the public and conform to the public aesthetics, which can ensure the effectiveness of the recreational activities, improve people's spiritual quality and life quality and create a good activity atmosphere for the environment development and construction.

\section{Case analysis of the construction of beautiful country public art in Weinan Region}

Based on the development process of Guanzhong village culture, this paper expounds the whole form, street space and architectural courtyard of the village, analyzes the characteristics of beautiful village and explores the methods for beautiful village public art construction from the perspective of the cultural heritage and traditional village relation.

\subsection{Unified planning}

We should respect the regional cultural characteristic and the original village texture, integrate the new elements while retaining the village historical and cultural style, Guanzhong folk culture, protecting the villagers' spiritual values, highlighting the regional folklore and having reasonable planning of the village settlement landscape for the beautiful village construction in Weinan Region, particularly the traditional village reform. We should remove the architecture affecting the integrity of village original appearance space, the illegal house and seriously damaged house in order to show the country flavor and improve its culture charm. We should guarantee the development of rural tourism in the Weinan Region, which can improve the local economic benefits and ensure the development of rural economy. It is also the basic purpose of beautiful village construction.

\subsection{Street space}

Village street, the traffic space of villagers and also the public space of activity, connects the residents and public buildings. We can remove the public building affecting the integrity of traffic and public space and design the landscape element and infrastructure with Guanzhong traditional elements in the main street space in order to avoid the complete cement pavement layout and increase the variation of streetscape, such as the stone roller, millstone, wainage, old well, etc. We should retain the gate pier, land niche, Taishan tablets and other Guanzhong cultures and inherit the cultural heritage in the Book of Songs. The rural living environment consists of people's living environment and public place. 
Particularly, it is of great importance to create traditional public activity place, such as the repair of the existing temples. The square of the temple can provide place for temple fair or villagers' gathering activity. The repair of the stage can better inherit intangible cultural heritage, such as the Huayin old opera. The memorial temple should be constructed because it is the spiritual place for villagers and also an important place to maintain clan relation. Below is the reference map of the rural landscape public art facility(Figure 2).

\subsection{Node shaping}

The nodes are mainly distributed at the starting point, finishing point and cross point of the main roads in the village in the overall space structure of the village. The overall form and structure of village relies on the node relation among village entrance, square and the old tree. We can set up special Guanzhong fort gate and memorial gateway at the entrance of the village, integrated with Guanzhong folk elements, which makes the village recognizable. It is characterized by regionalism and culture. The square is the central point of the whole village culture, exchange, leisure and trade. For example, Lingquan Village, Fang Town, Heyang County completes the "Impression Lingquan" square and the surrounding facilities on the basis of the Fushan Scenic Spot and Guanzhong traditional culture.

The landscape elements with natural symbol, regional symbol, cultural symbol and aesthetic symbol are constructed in other regions through the extraction, remodeling and application of the rural landscape element. The landscape element and village are integrated organically according to the overall appearance, space pattern and architecture of the village. Water culture themed rural landscape is one of the most significant elements of node shaping, reflecting people' s protection for the local water resource. The waterscapes in Weinan Region are special. There are dropping water terrace, quiet creek, etc as shown in Figure 3. All these are people' $s$ wisdom for the application of water resource.

\subsection{Architectural courtyard}

The beautiful village construction is closely associated with the Weinan traditional residential courtyard, architectural form, material and color characteristics. The courtyard adopts narrow courtyard type from north to south because Guanzhong is in the temperate zone with four distinct seasons, long winter and summer and hot summer. The narrow courtyard type can also be used in the new courtyard construction. New residents can set up colonnade around the narrow courtyard, which is called "Xie Yang" by the local people. The colonnade is the place for people's

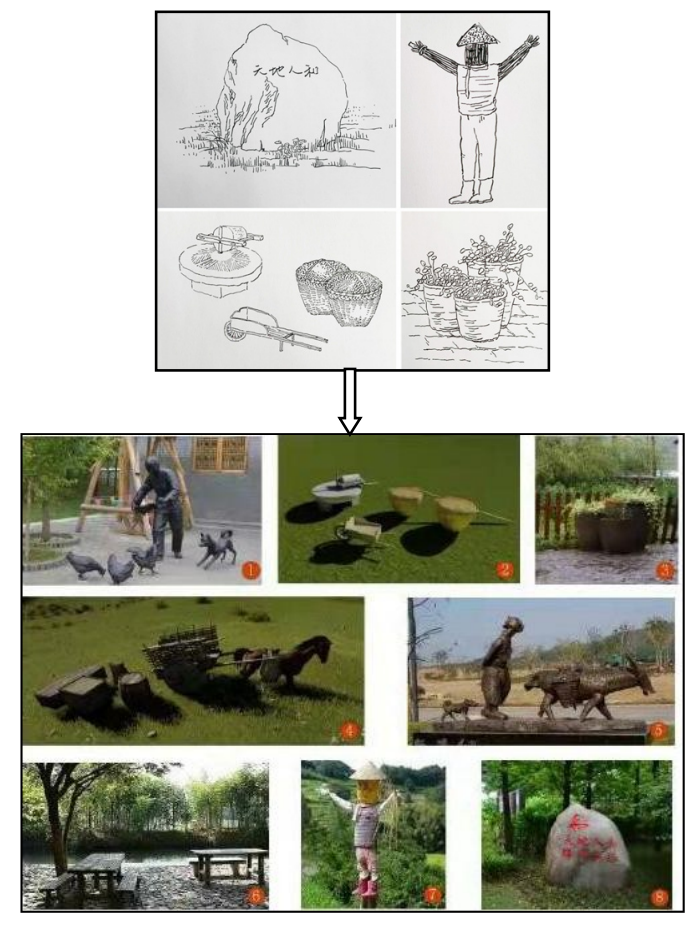

Figure2 Rural landscape public art facility

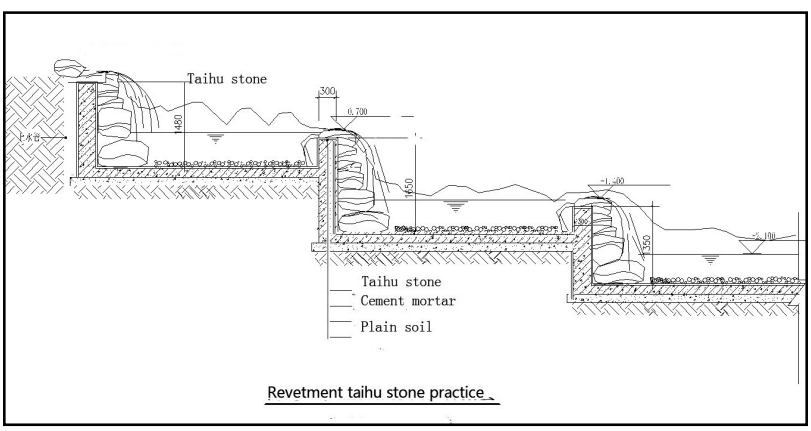

Fgure3 Construction drawing of dynamic waterscape

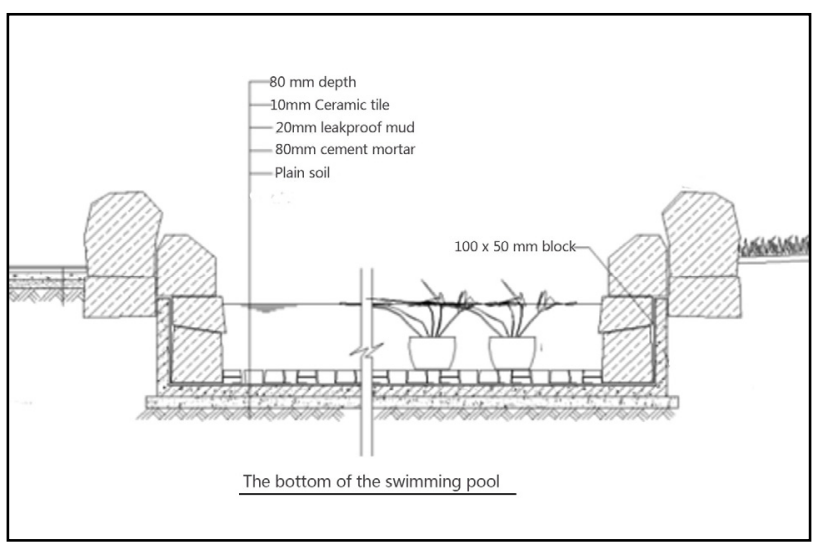

Figure4 Construction drawing of static waterscape

cultural activity and rest with the transport, sunshade and rain shelter. Located between the indoor and the courtyard, the colonnade can extend the indoor and outdoor space. At the same time, it enriches the space perception in the narrow courtyard, increases the complexity of the courtyard space and breaks the narrow rigid atmosphere. The corridor gate is set at both ends of the colonnade, such as the corridor gate of Hancheng and Anwu Village, Jingyang. It is found out that there are 
corridor gates in the courtyard in the traditional residence and also in the outside of gate, such as the architecture in Lingquan Village, Fang Town, Heyang County. We should use the special "half cover of house" in Guanzhong for the reform of architectures affecting the overall planning of the village. The inclined roof of the house in the courtyard leads the rainwater into the courtyard so as to facilitate the water storage because there is little rain in Guanzhong. It also has the implied meaning "Nourishing water won't flow into the farmland of others". The design in figure 5 reflects agricultural civilization in Guanzhong, the outlook on life and sense of happiness of cultivation culture. The pattern design of the bottom of swimming pool in Lingquan Village is full of local features. A large leaf shaped pattern covers the bottom of the pool, thus making people feel that as if they were wandering in the green forest(as shown in Figure 6).

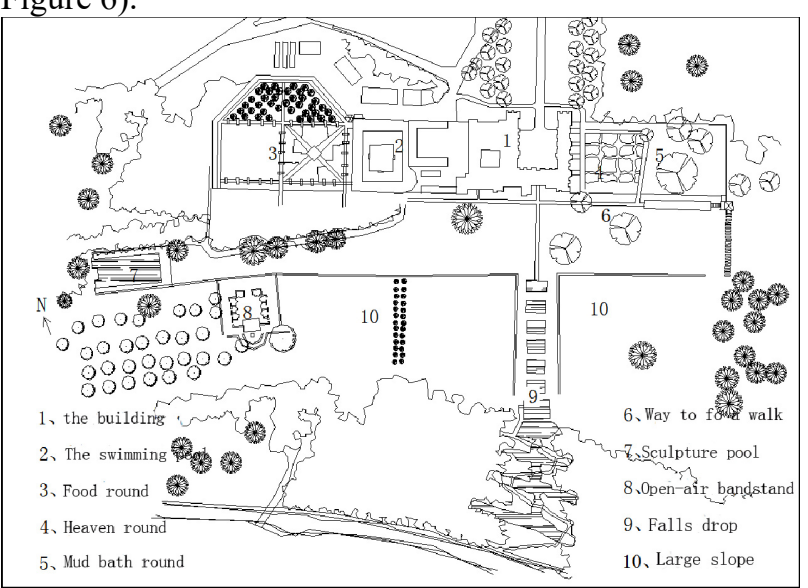

Figure 5 Residence courtyard layout in Guanzhong

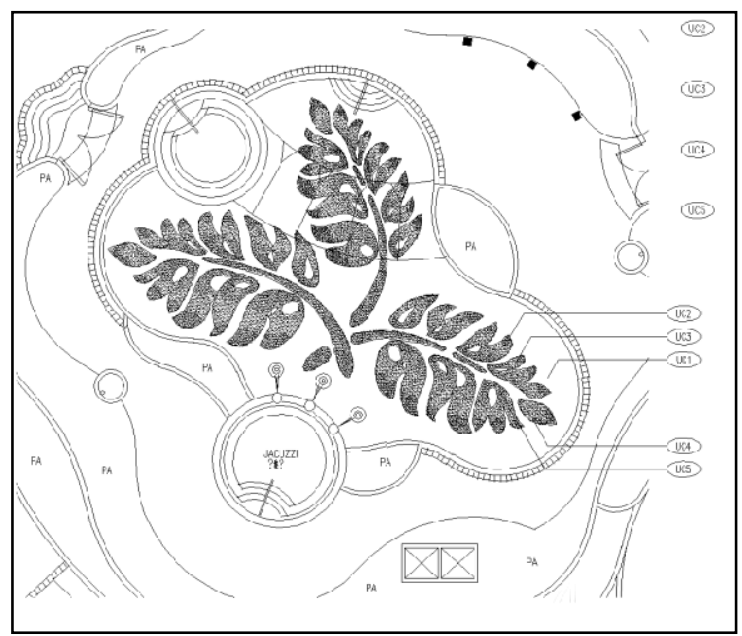

Figure 6 Swimming pool bottom pattern design

\subsection{Tourism positioning}

We should protect, explore and continue the Weinan historic culture resource, actively promote Weinan special beautiful village construction, enable villages to enjoy a good and prosperous life and promote the development of tourism economy while inheriting the traditional culture in Guanzhong. On the one hand, we can build the counties in Weinan into local traditional culture museums with the integration of intangible cultural heritage into the tangible village and retain the farming culture, fork culture and traditional craft so as to achieve the co-existence of beautiful village construction, rural intangible cultural heritage and traditional architecture environment as well as the harmony of environment, architecture, people. We are striving to form the beautiful village construction of "one village one product" and "one family and one art", such as the Dangjia Village in Hancheng. On the other hand, we can change the traditional residence into homestay, thus enabling the tourists to experience the traditional Chinese culture while staying in the homestay. We can create the art experience homestay of shadow play, pottery kneading, embroidery, etc, the vacation type homestay with natural or artificial landscape or the experience type homestay in traditional village. We can create the beautiful village of inheritance type in Weinan Region by using various original traditional culture in Guanzhong.

\subsection{Village landscape}

Village landscape is rural, farming, rural and dynamic, constantly changing and developing. We can grow local plant in order to retain Guanzhong traditional village special landscape and create seasonal farming culture landscape. Inheriting the traditional residence style of black brick and blue roofing tile, Lingquan Village aims to create the tourism route of " traditional ancient village, modern new village, impressive Lingquan and Fushan scenic spot" and the new travelling mode of "eating, living, appreciating and playing", thus forming village gathering landscape.A thatched pavilion reflects the atmosphere of farming, and the design of the connection between mountains and lakes should reflect the seasonal pastoral scenery through the arrangement of plants (e.g.7-8).

\section{Conclusion}

In the society at present, it can be seen that some traditional excellent national culture, rural regional culture as well as its inherent values, mode of thinking, technological skills and so on have given us a lot of enlightenment so far. More and more artists are getting to the village and turn their art fields into the village with the new trend of art circle in recent years. Currently, artists in China's three art colleges carry out the village art practices in Yangdeng Town, Guizhou, Bulu Village and Shijiezi Village, Gansu, integrating art into the beautiful village. It is beyond doubt that they are seeking a original rural 


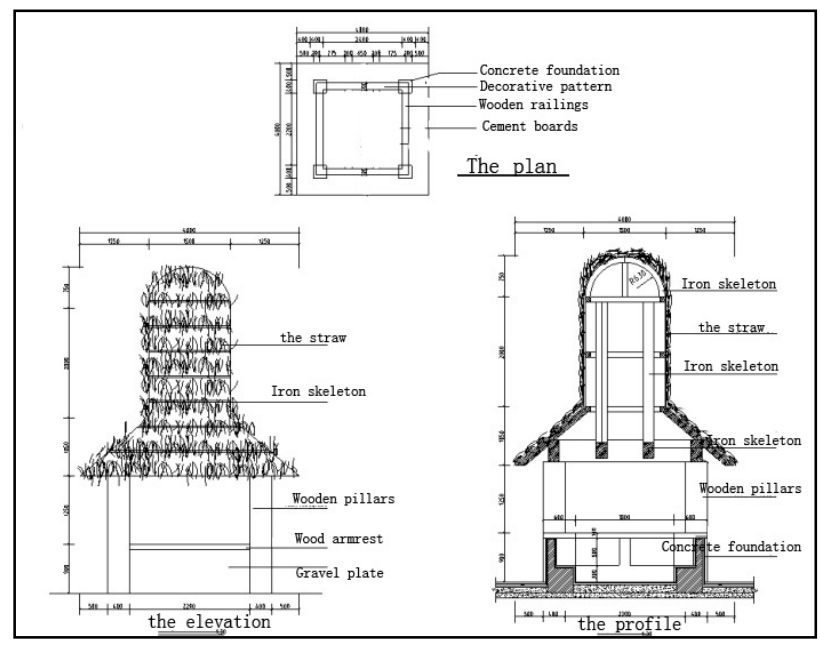

Figure 7 Construction drawing of thatch pavilion

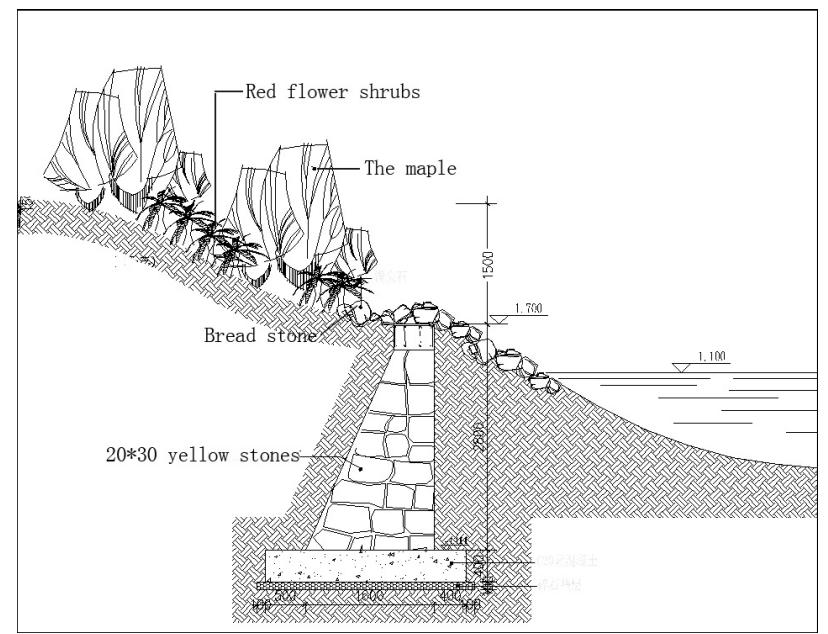

Figure8 Mountain lake line plant configuration pavilion

environment art road for the exploration and innovation of the rural environment construction through these art practices. It is a long term topic for the artistic development of the rural environment engineering that is worthy of exploration and creation in various fields. Only in this way can we develop and implement the rural environment construction based on the perspective of public art aesthetics.

\section{Reference}

1. Wang Yinghui. A Brief Analysis on the Art Aesthetics in Public Art Design [J]. Research on Aesthetic Education, 2018 (9): 193

2. Qin Feng. Study on the Feasibility of Public Art Intervention in Rural Greenway Construction [J]. Chinese Horticulture Abstracts, 2017 (6) : 141143

3. Zhou Chunmei. Analysis on Special Rural Construction in Contemporary China[J]. Journal of Guangxi Science \& Technology Normal University, 2017 (11) : 45 